\title{
Decomposition and Mineralization of Dimethyl Phthalate in an Aqueous Solution by Wet Oxidation
}

\author{
Dar-Ren Ji, ${ }^{1}$ Chia-Chi Chang, ${ }^{1}$ Shih-Yun Chen, ${ }^{1}$ Chun-Yu Chiu, ${ }^{2}$ \\ Jyi-Yeong Tseng, ${ }^{1}$ Ching-Yuan Chang, ${ }^{1,3}$ Chiung-Fen Chang, ${ }^{4}$ Sheng-Wei Chiang, ${ }^{5}$ \\ Zang-Sie Hung, ${ }^{1}$ Je-Lueng Shie, ${ }^{6}$ Yi-Hung Chen, ${ }^{7}$ and Min-Hao Yuan ${ }^{1,7}$ \\ ${ }^{1}$ Graduate Institute of Environmental Engineering, National Taiwan University, Taipei 106, Taiwan \\ ${ }^{2}$ Department of Cosmetic Science and Application, Lan Yang Institute of Technology, Yilan 261, Taiwan \\ ${ }^{3}$ Department of Chemical Engineering, National Taiwan University, Taipei 106, Taiwan \\ ${ }^{4}$ Department of Environmental Science and Engineering, Tunghai University, Taichung 407, Taiwan \\ ${ }^{5}$ Chemical Engineering Division, Institute of Nuclear Energy Research, Atomic Energy Council, Lungtan, Taoyuan 325, Taiwan \\ ${ }^{6}$ Department of Environmental Engineering, National Ilan University, Yilan 260, Taiwan \\ ${ }^{7}$ Department of Chemical Engineering and Biotechnology, National Taipei University of Technology, Taipei 106, Taiwan
}

Correspondence should be addressed to Ching-Yuan Chang; cychang3@ntu.edu.tw

Received 10 November 2014; Revised 23 May 2015; Accepted 10 June 2015

Academic Editor: Zulin Zhang

Copyright (C) 2015 Dar-Ren Ji et al. This is an open access article distributed under the Creative Commons Attribution License, which permits unrestricted use, distribution, and reproduction in any medium, provided the original work is properly cited.

Dimethyl phthalate (DMP) was treated via wet oxygen oxidation process (WOP). The decomposition efficiency $\eta_{\mathrm{DMP}}$ of DMP and mineralization efficiency $\eta_{\text {TOC }}$ of total organic carbons were measured to evaluate the effects of operation parameters on the performance of WOP. The results revealed that reaction temperature $T$ is the most affecting factor, with a higher $T$ offering higher $\eta_{\mathrm{DMP}}$ and $\eta_{\mathrm{TOC}}$ as expected. The $\eta_{\mathrm{DMP}}$ increases as rotating speed increases from 300 to $500 \mathrm{rpm}$ with stirring enhancement of gas liquid mass transfer. However, it exhibits reduction effect at $700 \mathrm{rpm}$ due to purging of dissolved oxygen by overstirring. Regarding the effects of pressure $P_{T}$, a higher $P_{T}$ provides more oxygen for the forward reaction with DMP, while overhigh $P_{T}$ increases the absorption of gaseous products such as $\mathrm{CO}_{2}$ and decomposes short-chain hydrocarbon fragments back into the solution thus hindering the forward reaction. For the tested $P_{T}$ of 2.41 to $3.45 \mathrm{MPa}$, the results indicated that $2.41 \mathrm{MPa}$ is appropriate. A longer reaction time of course gives better performance. At $500 \mathrm{rpm}, 483 \mathrm{~K}, 2.41 \mathrm{MPa}$, and $180 \mathrm{~min}$, the $\eta_{\mathrm{DMP}}$ and $\eta_{\mathrm{TOC}}$ are 93 and $36 \%$, respectively.

\section{Introduction}

Phthalic acid esters (PAEs) including dimethyl phthalate (DMP) are major plasticizer to improve the mechanical properties of polymers. These polymers in turn were used for making tableware such as forks, spoons, dishes, cups, and lunchboxes. In fact, the PAEs are added via noncovalent bonding with the polymers. It means PAEs are easily released to the hot soup, heated food, and oily contents from the tableware and are orally ingested daily $[1,2]$.

PAEs are endocrine disrupter substances (EDSs) too. Their derivatives exhibit the similar structure with endocrine of human and other animals, thus inducing the possibility of cancer of human and the sex development of male. The worst influence of EDSs to the ecosystem would be extinction for endanger species $[3,4]$.

Although PAEs can be effectively removed from the aqueous phase by adsorption [5] which also has been applied to treat other EDSs $[6,7]$, it needs the regeneration of exhausted adsorbent and the post treatment of concentrated regeneration solution. Activated sludge based biological sewage treatment system needs $20 \mathrm{~d}$ to reach $71 \%$ mineralization efficiency and is not beneficial to deal with toxic DMP. It was biodegraded to monomethyl phthalate (MMP) and phthalic acid (PA) after treatment of $2.5 \mathrm{~d}$ [8-10]. Some advanced solutions were proposed such as photolysis [11-13], photocatalysis 
[11-15], electrochemical $[16,17]$, and oxidant-added oxidation $[11,14,18,19]$ methods. Most of these treatments need postbiological process to further mineralize the decomposed compounds. The unconsumed oxidant residue needs to be neutralized for matching the effluent standard $[14,15]$. Processes of wet air oxidation (WAP) and wet oxygen oxidation (WOP) with (CWAP and CWOP) and without catalysts have been successfully employed for oxidation treatments [20-30]. For example, in a study on the treatment of high-strength industrial wastewater, Lin and Ho [27] reported that the chemical oxygen demand (COD) removal efficiencies $\left(\eta_{\mathrm{COD}}\right)$ via WAP, WOP, and CWAP with $\mathrm{CuSO}_{4}$ catalyst were 65,73 , and $75 \%$, respectively, at $473 \mathrm{~K}, 3 \mathrm{MPa}, 300 \mathrm{rpm}, 1 \mathrm{~L} / \mathrm{min}$ gas flow rate, and $2 \mathrm{~h}$. The application of WAP and WOP has the advantages avoiding the posttreatment of unwanted residual oxidant species and no need for the recovery and regeneration of catalyst, compared with oxidant-added oxidation and catalytic oxidation, respectively. The abundant dissolved oxygen left can improve the performance of regular biological sewage system if needed [18]. Moreover, WOP gives $\eta_{\text {COD }}$ only slightly less than catalytic oxidation while higher than WAP. This study thus employed WOP to treat the DMPcontaining aqueous solution.

\section{Experimental Materials and Methods}

2.1. Materials. DMP with purity of $99.5 \%$ was supplied by Hayashi Pure Chemical Industries Ltd. (Osaka, Japan). The mobile phase of high performance liquid chromatography (HPLC) was composed as acetonitrile $\left(\mathrm{CH}_{3} \mathrm{CN}\right)$ : DI water = $1: 1$, where acetonitrile of $100 \%$ purity was from J. T. Baker, Phillipsburg, NJ. The solvent for apparatus cleaning is acetone $\left(\mathrm{C}_{3} \mathrm{H}_{4} \mathrm{O}\right)$ with purity of $99.5 \%$ by Mallinckrodt Chemicals, $\mathrm{St}$. Louis, MD. The reagents for measurement of total organic carbon (TOC) were (1) carrier gas: $99.99 \% \mathrm{~N}_{2}$ from San Fu Chemical Co. Ltd., Taipei, Taiwan; (2) oxidant: sodium peroxydisulfate, $\mathrm{Na}_{2} \mathrm{~S}_{2} \mathrm{O}_{8}$ ( $99 \%$ purity), from Nacalai Tesque, Kyoto, Japan; (3) standard solution: anhydrous potassium biphthalate, $\mathrm{KHP}, \mathrm{C}_{8} \mathrm{H}_{5} \mathrm{KO}_{4}$ (99.0\% purity), from Riedel-de Haën, Seelze, Germany. The reaction gas $\mathrm{O}_{2}$ (99.99\% purity) and air $\left(\mathrm{O}_{2}: \mathrm{N}_{2}=20: 80,99.99 \%\right.$ purity) were purchased from San Fu Chemical Co. Ltd., Taipei, Taiwan.

2.2. Methods. The pressurized autoclave reaction system is shown in Figure 1. A $1 \mathrm{~L}$ bench top reactor is used. It is made of stainless steel 316 and equipped with a stirring rotor (DC-2RT44, Hsing-Tai Machinery Ind. Co., Taipei, Taiwan), pressure display module, and K-type thermal couple. The temperature of heater (Model-TC-10A, Macro Fortunate, Taipei, Taiwan) is controlled with temperature controller (Model-BMW-500, Newlab Instrument Co., Taipei, Taiwan). Mass flow controller of Model 5850E manufactured by Brooks (Hatfield, PA) is employed to control the gas flow rate. The bearing is cooled by cooling water from circulating bath (Model-B403, Firstek Scientific, Taipei, Taiwan). The upper cap of vessel has six holes with five for two sampling valves, thermal couple, pressure gauge, and release valve, while one for spare port. The experiments were batch type with volume
TABLE 1: Operation parameters and range of WOP.

\begin{tabular}{lc}
\hline Parameter of operation & Operation range \\
\hline Rotation speed Nr, rpm & $300,500,700$ \\
Temperature $T, \mathrm{~K}$ & $463,473,483$ \\
Pressure $P_{T}, \mathrm{MPa}$ & $2.41,2.67,3.10,3.45$ \\
Working gas of $\mathrm{O}_{2}$ & Pure $\mathrm{O}_{2}$ \\
\hline
\end{tabular}

of liquid of DMP solution $\left(V_{L}\right)$ of $400 \mathrm{~mL}$. The sampling valves are connected to cooling coil. The pressured vapor was captured to the coil and then cooled while keeping the pressure of the reactor. After $5 \mathrm{~mL}$ liquor was sampled, the noncollected cooled liquid was conducted back to the reactor.

The initial concentration $\left(C_{0}\right)$ of DMP solution was $100 \mathrm{mg} / \mathrm{L}$. The concentrations of DMP of samples $(C)$ were analyzed by high performance liquid chromatography (HPLC, Viscotek Model 500, Houston, TX), while those of total organic carbon (TOC) were analyzed by TOC analyzer (Model 1010, O.I. Analytical, NY). The column of HPLC is $516 \mathrm{C}-18$ of $25 \mathrm{~cm} \times 4.6 \mathrm{~mm}$ with ID $5 \mu \mathrm{m}$ (Supelco Inc., Bellefonte, PA). The TOC analyzer uses nondispersive infrared (NDIR) detector, with carrier gas of $\mathrm{N}_{2}$, oxidative agent of $10 \%$ sodium peroxydisulfate solution, and TOC standard solution of anhydrous potassium biphthalate. The precision of experimental data was indicated in figures by error bar with standard deviation $\left(\sigma_{n-1}\right)$ above and below the average value.

The batch WOP process was performed in two stages. The first is heating stage. The DMP-containing solution, which was prebubbled by $\mathrm{N}_{2}$ to purge out the residual oxygen, was filled into the autoclave reactor and then heated from room temperature $283 \mathrm{~K}$ to the set reaction temperature $(T)$ without any oxidant. The tested temperatures were 463, 473, and $483 \mathrm{~K}$. The initial time $(t)$ was noted as $0_{i}$, while the final time of the first stage as $0_{f}$. In the second stage, the working gas $\mathrm{O}_{2}$ was introduced into the reactor at $t=0_{f}$ to the desired operation pressure $\left(P_{T}\right)$ to continue the oxygen oxidation reaction.

The major operation parameters of batch WOP were examined including (1) the stirring speed $(\mathrm{Nr}),(2)$ reaction temperature $T$, and (3) operation pressure $P_{T}$. The initial $\mathrm{pH}$ value $\left(\mathrm{pH}_{0}\right)$ was not adjusted while reflected by the $C_{0}$. Values of parameters are listed in Table 1 referring to those of others [27, 29]. For example, Lin and Ho [27] performed the experiments with $\mathrm{Nr}=100-400 \mathrm{rpm}, P_{T}=2.5-5.0 \mathrm{MPa}$, and $T=423-513 \mathrm{~K}$. They reported that (1) $300 \mathrm{rpm}$ and $3 \mathrm{MPa}$ were appropriate and (2) $T$ was the most important operation variable with marginal enhancing effect for $T$ above $498 \mathrm{~K}$. The present study extended $\mathrm{Nr}$ to $500-700 \mathrm{rpm}$, while it employed $P_{T}$ and $T$ in the proper ranges of those of Lin and Ho [27].

\section{Results and Discussion}

3.1. Effects of Rotation Speeds Nr. Figure 2 illustrate the variation of decomposition efficiency of DMP ( $\left.\eta_{\text {DMP }}\right)$ with reaction time $t$ at various rotation speeds $(\mathrm{Nr}=300,500$, 


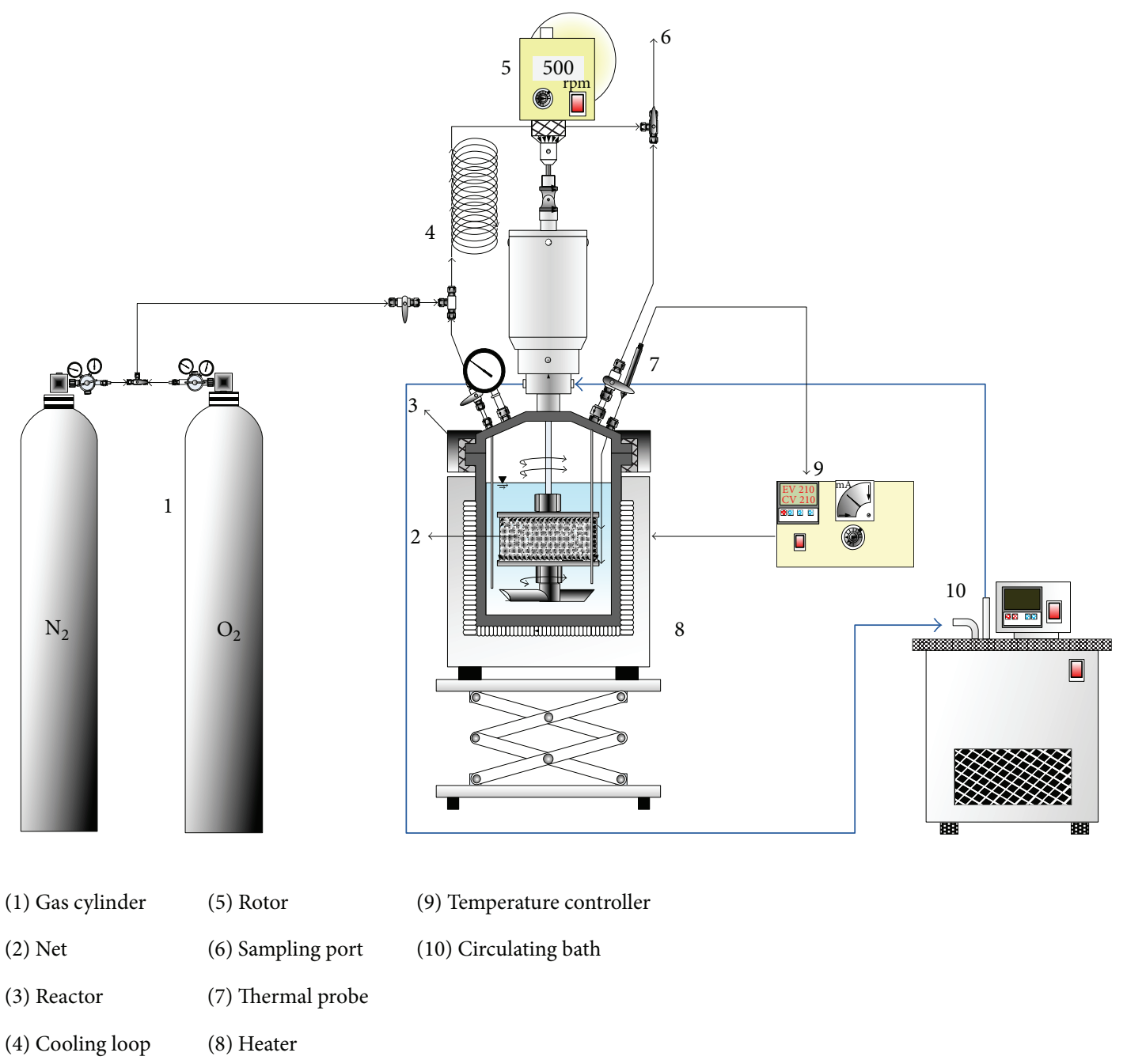

FIGURE 1: Schematic diagram of wet oxygen oxidation system.

and $700 \mathrm{rpm})$. Other conditions are reaction temperature $T$ $=473 \mathrm{~K}$ and operation pressure $P_{T}=2.41 \mathrm{MPa}$. As expected, more DMP is decomposed with longer $t$ giving higher $\eta_{\mathrm{DMP}}$. The $\eta_{\text {DMP }}$ is 66,78 , and $66 \%$ at $t=180 \mathrm{~min}$ for $\mathrm{Nr}=300$, 500 , and $700 \mathrm{rpm}$, respectively. In general, a good gas liquid mixing assists the reaction. Thus, an increase of $\mathrm{Nr}$ from 300 to $500 \mathrm{rpm}$ increases the gas liquid mass transfer and offers a higher $\eta_{\text {DMP }}$. However, the dissolved oxygen needed for reaction may be tripped or purged out from liquid to gas as further increasing the $\mathrm{Nr}$, say to $700 \mathrm{rpm}$, reducing the $\eta_{\mathrm{DMP}}$. The $\mathrm{Nr}$ of $500 \mathrm{rpm}$ leads to better increasing trend of $\eta_{\mathrm{DMP}}$.

It is noted that although the effects of $\mathrm{Nr}$ of low rpm, say below $300 \mathrm{rpm}$, on the system performance were not investigated in this study, its qualitative effects may be realized referring to the work of Lin and Ho [27] dealing with the treatment of high-strength industrial wastewater. They examined the effects of $\mathrm{Nr}$ from 100 to $400 \mathrm{rpm}$ on the chemical oxygen demand removal efficiencies $\eta_{\mathrm{COD}}$, indicating apparently significant effect as Nr below $300 \mathrm{rpm}$. An Nr of $300 \mathrm{rpm}$ was thus adopted for their further experiments. This thus justified the adoption of $500 \mathrm{rpm}$ for the followed experiments of the present study, assuring the good mixing.

The effect of reaction time on the $\mathrm{pH}$ value of DMPcontaining solution during WOP at different $\mathrm{Nr}$ is depicted in Figure 3. The decrease of $\mathrm{pH}$ value as oxidation decomposition takes place indicates the formation of acidic products. Although the decompositions are significant from 60 to $180 \mathrm{~min}$ as shown in Figure 2, the $\mathrm{pH}$ value stays nearly the same at about 4 after $60 \mathrm{~min}$. This might be due to the cause that some intermediate acidic products from the decomposition of DMP are further broken down to small acidic fragments of low solubility being released to gas phase, leaving the $\mathrm{pH}$ value of liquid essentially not altered for $t$ longer than $60 \mathrm{~min}$. The negligible effect of $\mathrm{Nr}$ on $\mathrm{pH}$ value as $\mathrm{Nr}$ is sufficiently high as $300 \mathrm{rpm}$ or higher might be attributed to the balance of enhancement of gas liquid mass transfer and the purge of small acidic fragments by rotation stirring. 


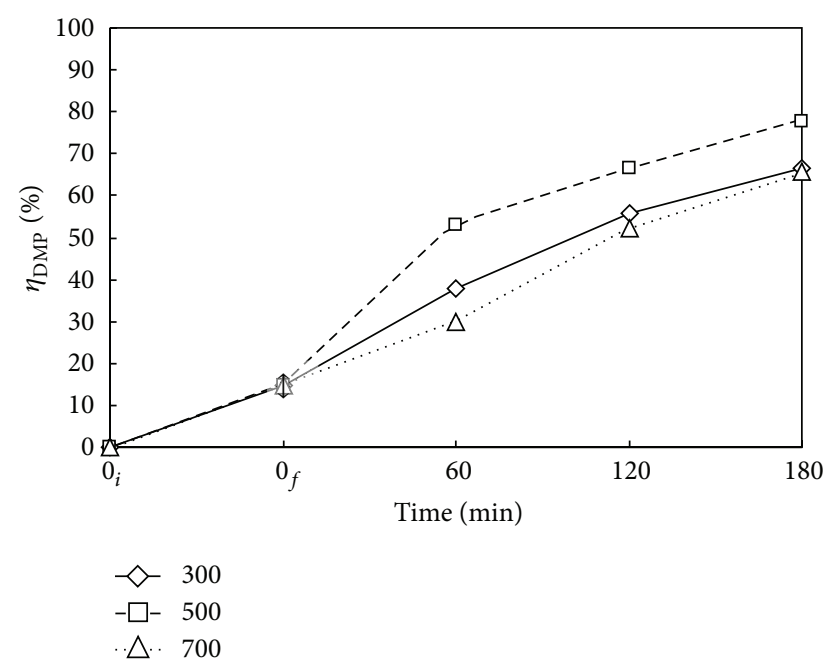

FIgURE 2: Time variation of decomposition efficiency of DMP $\left(\eta_{\mathrm{DMP}}\right)$ via $\mathrm{WOP}$ at various rotating speeds $\mathrm{Nr} . \diamond, \square$, and $\triangle: \mathrm{Nr}=$ 300,500 , and $700 \mathrm{rpm} . C_{0}=100 \mathrm{mg} \mathrm{L}^{-1}, V_{L}=400 \mathrm{~mL}, T=473 \mathrm{~K}$, and $P_{T}=2.41 \mathrm{MPa}$. Working gas after time $=0_{f}$ is $\mathrm{O}_{2}$. $\uparrow$ : Mean and Standard deviation (SD, $n-1$ method) at $t=0_{f}: 14.8 \pm 2.8$.

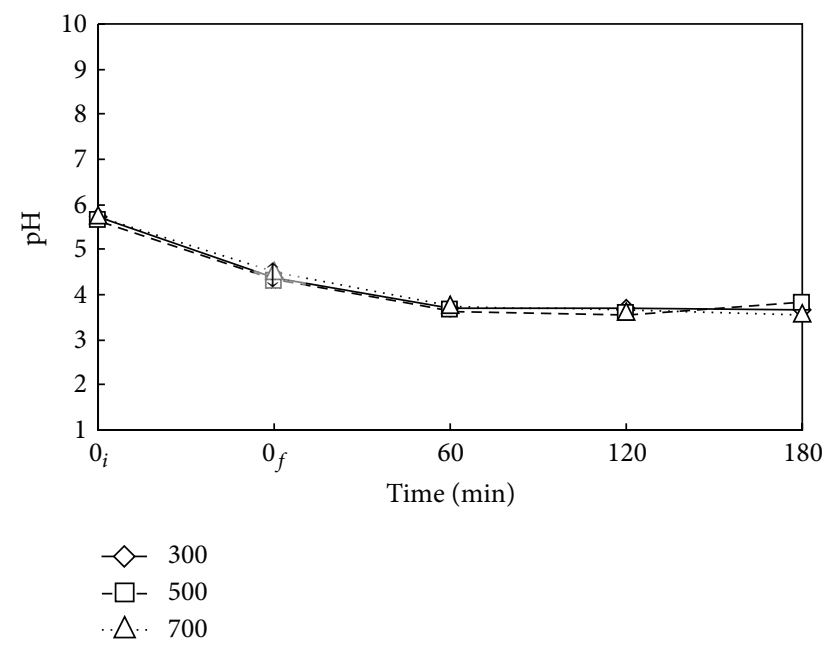

FIGURE 3: Time variation of $\mathrm{pH}$ value for the decomposition of DMP via WOP at various $\mathrm{Nr} . \diamond, \square$, and $\triangle: \mathrm{Nr}=300,500$, and $700 \mathrm{rpm} . C_{0}$ $=100 \mathrm{mg} \mathrm{L}^{-1}, V_{L}=400 \mathrm{~mL}, T=473 \mathrm{~K}$, and $P_{T}=2.41 \mathrm{MPa}$. Working gas after time $=0_{f}$ is $\mathrm{O}_{2}$. $\uparrow$ : Mean and Standard deviation (SD, $n-1$ method) at $t=0_{f}: 4.4 \pm 0.1$.

3.2. Effects of Reaction Temperature T. Figures 4 and 5 show the time variations of $\eta_{\mathrm{DMP}}$ and $\eta_{\mathrm{TOC}}$ at reaction temperatures $T$ of 463,473 , and $483 \mathrm{~K}$ for the case with $\mathrm{Nr}=500 \mathrm{rpm}$ and $P_{T}=2.41 \mathrm{MPa}$. In the heating period from $0_{i}$ to $0_{f}$ without oxidant, DMP underwent mainly the hydrothermal decomposition accompanied with slight mineralization. The $\eta_{\mathrm{DMP}}$ is $17 \%$ for 463 and $473 \mathrm{~K}$ while $45 \%$ for $483 \mathrm{~K}$ at the end of heating period with no oxygen. The decomposition of DMP is very vigorous at high temperature. But the $\eta_{\text {TOC }}$ is lower than $10 \%$ for all three temperatures because of the oxidant lack. With the presence of oxygen, the $\eta_{\text {DMP }}$ was greatly enhanced

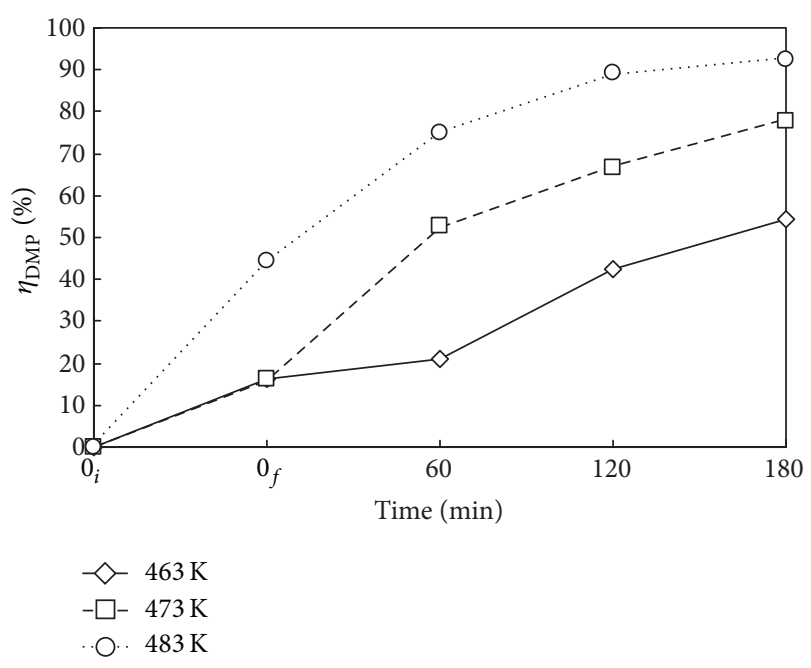

FIGURE 4: Time variation of $\eta_{\text {DMP }}$ via WOP at various temperatures $T . \diamond, \square$, and $\bigcirc: T=463,473$, and $483 \mathrm{~K} . C_{0}=100 \mathrm{mg} \mathrm{L}^{-1}, V_{L}=$ $400 \mathrm{~mL}, P_{T}=2.41 \mathrm{MPa}$, and $\mathrm{Nr}=500 \mathrm{rpm}$. Working gas after time $=$ $0_{f}$ is $\mathrm{O}_{2}$.

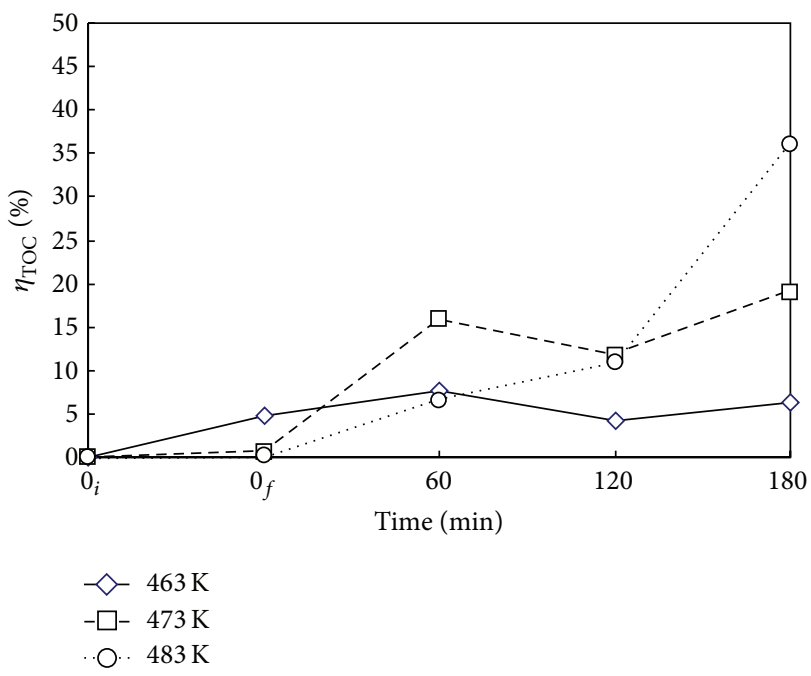

FIGURE 5: Time variation of mineralization efficiency of DMP ( $\left.\eta_{\text {TOC }}\right)$ via WOP at various $T . \diamond, \square$, and $\bigcirc: T=463,473$, and $483 \mathrm{~K} . C_{0}=$ $100 \mathrm{mg} \mathrm{L}^{-1}, V_{L}=400 \mathrm{~mL}, P_{T}=2.41 \mathrm{MPa}$, and $\mathrm{Nr}=500 \mathrm{rpm}$. Working gas after time $=0_{f}$ is $\mathrm{O}_{2}$.

while $\eta_{\text {TOC }}$ moderately improved. The results indicated the low reactivity of acidic product fragments with oxygen. As expected, both $\eta_{\mathrm{DMP}}$ and $\eta_{\mathrm{TOC}}$ increased as reaction time and temperature increased. At $T=483 \mathrm{~K}$ and $t=180 \mathrm{~min}$, the $\eta_{\mathrm{DMP}}$ and $\eta_{\text {TOC }}$ were 93 and 36\%, respectively.

Figure 6 demonstrates the variation of $\mathrm{pH}$ value with time at various temperatures. As in Figure 3 , the $\mathrm{pH}$ value decreased with time, while it levels off at a longer time depending on the temperature, for example, at $60 \mathrm{~min}$ for higher temperatures of 473 and $483 \mathrm{~K}$ while at $120 \mathrm{~min}$ for lower temperature of $464 \mathrm{~K}$. Thus, a higher temperature case promotes the decomposition reaction, generally lowering and 


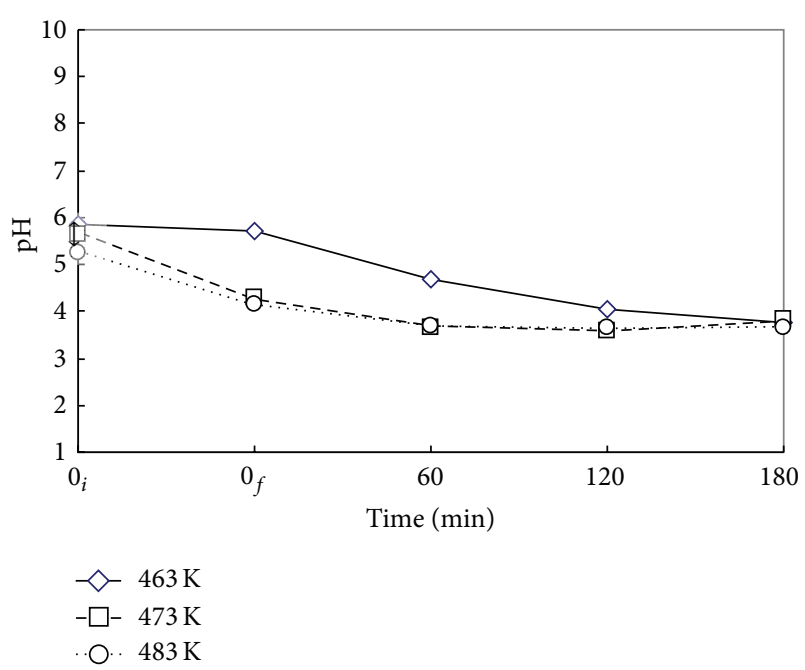

Figure 6: Time variation of $\mathrm{pH}$ value for the decomposition of DMP via WOP at various $T . \diamond, \square$, and $\bigcirc: T=463,473$, and $483 \mathrm{~K} . C_{0}=$ $100 \mathrm{mg} \mathrm{L}^{-1}, V_{L}=400 \mathrm{~mL}, P_{T}=2.41 \mathrm{MPa}$, and $\mathrm{Nr}=500 \mathrm{rpm}$. Working gas after time $=0_{f}$ is $\mathrm{O}_{2}$. $\uparrow$ : Mean and Standard deviation (SD, $n-1$ method) at $t=0_{i}: 5.6 \pm 0.3$.

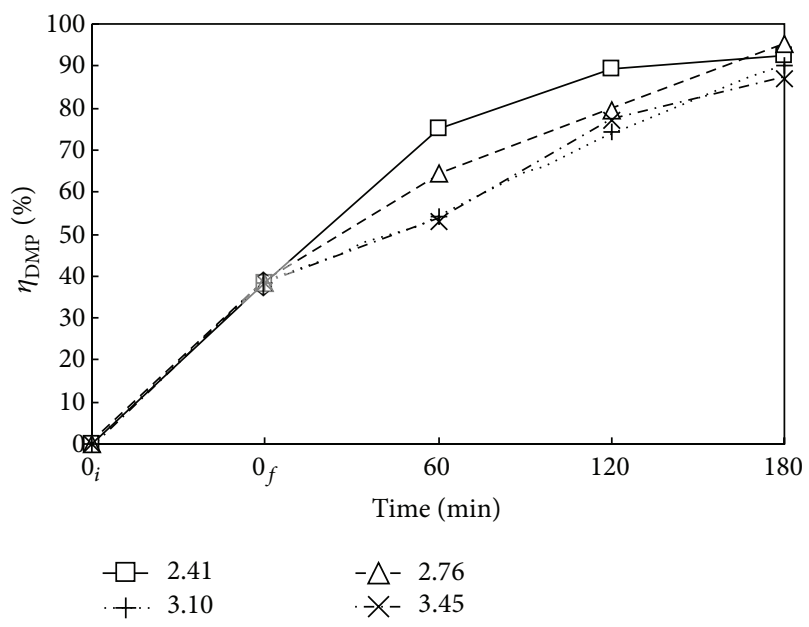

FIGURE 7: Time variation of $\eta_{\text {DMP }}$ via WOP at various pressures. $\square$, $\triangle$, +, and $\times: P_{T}=2.41,2.76,3.10$, and $3.45 \mathrm{MPa} . C_{0}=100 \mathrm{mg} \mathrm{L}^{-1}, V_{L}$ $=400 \mathrm{~mL}, T=483 \mathrm{~K}$, and $\mathrm{Nr}=500 \mathrm{rpm}$. Working gas after time $=$ $0_{f}$ is $\mathrm{O}_{2} . \uparrow$ : Mean and Standard deviation (SD, $n-1$ method) at $t=$ $0_{f}: 38.2 \pm 5.3$.

leveling the $\mathrm{pH}$ value faster than the lower temperature case. For $483 \mathrm{~K}$, the $\mathrm{pH}$ value decreases to a leveling value of around 4 after $60 \mathrm{~min}$.

3.3. Effects of Operation Pressure $P_{T}$. Figures 7 and 8 present the $\eta_{\text {DMP }}$ and $\eta_{\text {TOC }}$ versus time at $P_{T}$ of $2.41,2.76,3.10$, and $3.45 \mathrm{MPa}$ with $\mathrm{Nr}=500 \mathrm{rpm}$ and $T=483 \mathrm{~K}$. Both $\eta_{\mathrm{DMP}}$ and $\eta_{\text {TOC }}$ increase with time as expected. The oxygen was filled to reach the desired pressure right after heating period, that is, at $t=0_{f}$. There is no oxidant in the time period from $0_{i}$ to $0_{f}$. The DMP is hydrothermally decomposed in heating

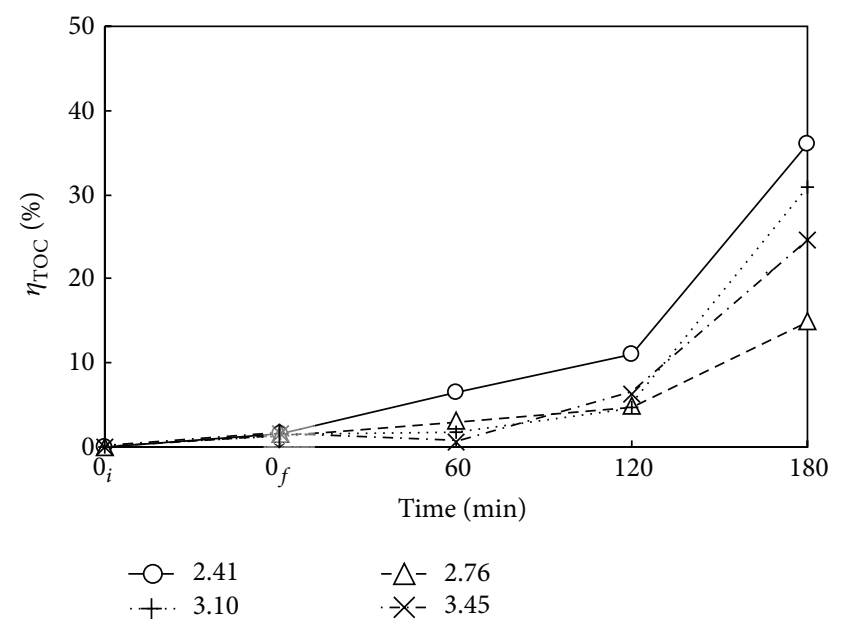

FIGURE 8: Time variation of $\eta_{\text {TOC }}$ via WOP at various pressures. $\bigcirc$, $\triangle$, + , and $\times: P_{T}=2.41,2.76,3.10$, and $3.45 \mathrm{MPa} . C_{0}=100 \mathrm{mg} \mathrm{L}^{-1}, V_{L}$ $=400 \mathrm{~mL}, T=483 \mathrm{~K}$, and $\mathrm{Nr}=500 \mathrm{rpm}$. Working gas after time = $0_{f}$ is $\mathrm{O}_{2}$. $\uparrow$ : Mean and Standard deviation (SD, $n-1$ method) at $t=$ $0_{f}: 1.5 \pm 1.3$.

period, giving $\eta_{\mathrm{DMP}}$ of around 33 to $45 \%$. The DMP is only slightly mineralized with low $\eta_{\text {TOC }}$ of about 0.3 to $3.1 \%$. In the presence of oxygen, both $\eta_{\text {DMP }}$ and $\eta_{\text {TOC }}$ are enhanced as decomposition and mineralization proceed. The oxidative decomposition of DMP essentially consists of two-stage reversible reactions as illustrated in Figure 10, which is discussed in the next section. The decomposition of DMP and intermediates to short-chain aliphatic acid and then $\mathrm{CO}_{2}$ are proposed by referring to the mechanism for the ozonation of DMP with UV and catalyst presented by Chang et al. [11]. An increase of oxygen as well as temperature enhances the forward reactions toward mineralization way, while the accumulation of $\mathrm{CO}_{2}$ reversely inhibits the mineralization according to Le Chatelier's principle [31]. Thus, sufficient oxygen with satisfactorily high $P_{T}$ is needed to ensure the forward oxidative decomposition reaction of DMP. For example, $P_{T}$ at $2.41 \mathrm{MPa}$ yields $\eta_{\mathrm{DMP}}$ and $\eta_{\mathrm{TOC}}$ of 93 and $36 \%$ at $180 \mathrm{~min}$, respectively. Although higher $P_{T}$ with more oxygen favors the forward decomposition reaction of DMP by oxygen, the absorption of accumulated gaseous products such as $\mathrm{CO}_{2}$ and decomposed short-chain hydrocarbon fragments in the closed reaction system increases as $P_{T}$ increases. The reabsorption of gaseous products back into the solution thus inhibits the forward reaction. Hence, as indicated in Figures 7 and $8, P_{T}$ of $2.41 \mathrm{MPa}$ is more appropriate than those of 2.76 to $3.45 \mathrm{MPa}$.

Figure 9 plots $\mathrm{pH}$ value versus time at various $P_{T}$. The reduction of $\mathrm{pH}$ value in hydrothermal decomposition period is more vigorous than that in the oxidative decomposition period. The trend is similar to that of Figure 3 previously discussed. The increase of $P_{T}$ higher than $2.41 \mathrm{MPa}$ exhibits negligible effect on the $\mathrm{pH}$ value. The $\mathrm{pH}$ value levels off, indicating the limited oxidative mineralization to $\mathrm{CO}_{2}$ and the gas liquid absorption balance of acidic compounds of $\mathrm{CO}_{2}$ and decomposed short-chain hydrocarbon fragments. 
TABLE 2: Comparison with some results of others for the decomposition of DMP via various methods.

\begin{tabular}{|c|c|c|}
\hline Study & Method & Result \\
\hline Bauer et al. [1] & $\begin{array}{l}\text { Anaerobic process in field municipal landfill } \\
\text { leachates }\end{array}$ & $\begin{array}{l}\text { DMP was completely hydrolysis to phthalic acid } \\
\text { but no cleavage for aromatic ring at different } \mathrm{pH} \\
\text { values }\end{array}$ \\
\hline Wang et al. [16] & $\begin{array}{l}\text { Electro-Fenton methods by electrodes: traditional } \\
\text { graphite cathode (G), carbon nanotube sponge } \\
\text { (CNTS), and graphite gas diffusion electrode } \\
\text { (GDE) }\end{array}$ & $\eta_{\text {TOC }}:$ G, $15 \%$; GDE, 35\%; CNTS, $75 \%$ \\
\hline Souza et al. [17] & $\begin{array}{l}\text { Electrochemical oxidation on } \mathrm{F} \text {-doped } \mathrm{Ti} / \beta-\mathrm{PbO}_{2} \\
\text { anode in filter press reactor }\end{array}$ & $\begin{array}{l}\text { DMP was completely decomposed under } \\
\text { electrolyte } \mathrm{Na}_{2} \mathrm{SO}_{4} \text { and low current densities } \\
(10 \mathrm{~mA}), \eta_{\text {TOC }}=25 \%\end{array}$ \\
\hline Chang et al. [11] & $\begin{array}{l}\text { Catalytic ozonation (OZ) in high-gravity rotating } \\
\text { packed bed (HG) with catalyst }\left(\mathrm{Pt} /-\mathrm{Al}_{2} \mathrm{O}_{3}\right) \text { and } \\
\text { ultraviolet }(\mathrm{UV}) \text { (mix of UV-C, } \mathrm{UV}-\mathrm{B} \text {, and UV-A } \\
\text { with } 200-280,280-315 \text {, and } 315-400 \mathrm{~nm} \text { and with } \\
\text { intensities of } 3.73,1.59 \text {, and } 3.99 \mathrm{~W} \mathrm{~m}^{-2} \text { ) }\end{array}$ & $\begin{array}{l}\eta_{\text {DMP }} \text { at } 50 \text { min: near } 100 \% \text { for Pt-OZ and } \\
\text { UV-Pt-OZ } \\
\eta_{\text {TOC }} \text { at } 1 \mathrm{~h}: 45 \%(\mathrm{OZ}) ; 56 \%(\mathrm{UV}-\mathrm{OZ}) ; 57 \% \\
\text { (Pt-OZ); } 68 \%(\mathrm{UV}-\mathrm{Pt}-\mathrm{OZ})\end{array}$ \\
\hline Chen et al. [13] & $\begin{array}{l}\text { Photocatalytic degradation using magnetic } \\
\text { poly(methyl methacrylate) (mPMMA) and UV } \\
254 \mathrm{~nm}\end{array}$ & $\begin{array}{l}\eta_{\mathrm{DMP}} \text { at } 4 \mathrm{~h}: 55-100 \% \text { via } \mathrm{TiO}_{2} / \mathrm{mPMMA}(\mathrm{C} 1) ; \\
68-100 \% \text { via } \mathrm{Pt}-\mathrm{TiO}_{2} / \mathrm{mPMMA}(\mathrm{C} 2) \\
\eta_{\mathrm{TOC}} \text { at } 4 \mathrm{~h}: 7.5-37.5 \% \text { via } \mathrm{C} 1 ; 1-64 \% \text { via } \mathrm{C} 2 \\
\end{array}$ \\
\hline Chen et al. [19] & $\begin{array}{l}\text { Photocatalytic ozonation using } \mathrm{TiO}_{2}, \mathrm{Al}_{2} \mathrm{O}_{3} \text {, and } \\
\mathrm{TiO}_{2} / \mathrm{Al}_{2} \mathrm{O}_{3} \text { catalysts }\end{array}$ & $\begin{array}{l}\eta_{\text {DMP }} \text { at } 30 \text { min: } 2-22 \% \text { without } \mathrm{O}_{3}, 90-100 \% \text { with } \\
\mathrm{O}_{3} \cdot \eta_{\text {TOC }}: 16-93 \%, 32-97 \% \text { at } 1,4 \mathrm{~h}\end{array}$ \\
\hline Chen et al. [12] & Photocatalysis using magnetic $\mathrm{Pt}-\mathrm{TiO}_{2} / \mathrm{mPMMA}$ & $\begin{array}{l}\text { UV } 185 \mathrm{~nm} \text { contributes better removal efficiency } \\
\text { than UV } 254 \mathrm{~nm}\end{array}$ \\
\hline This study & Wet oxygen oxidation & $\begin{array}{l}\eta_{\mathrm{DMP}} \text { and } \eta_{\mathrm{TOC}} \text { are } 93 \text { and } 36 \% \text { at } \mathrm{Nr}=500 \mathrm{rpm}, \\
T=483 \mathrm{~K}, P_{T}=2.41 \mathrm{MPa} \text {, and } t=180 \mathrm{~min}\end{array}$ \\
\hline
\end{tabular}

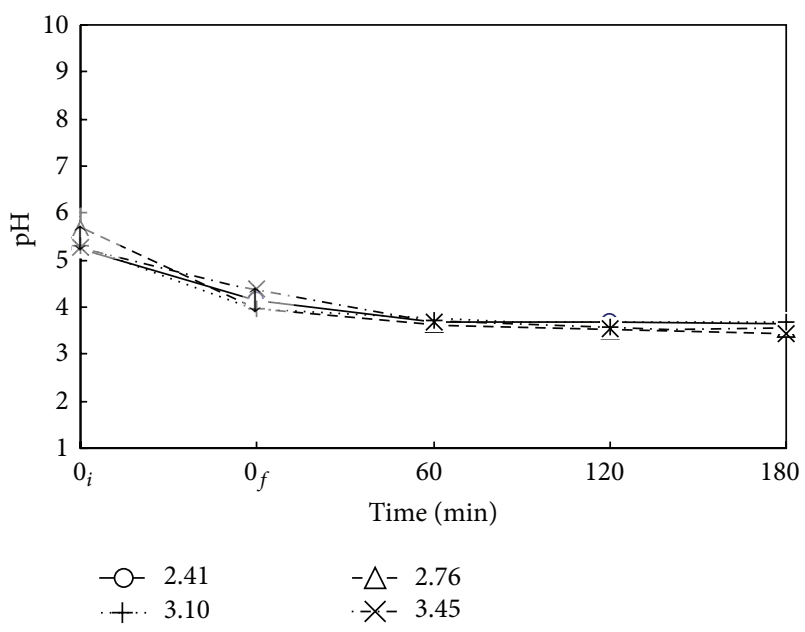

FIgURE 9: Time variation of $\mathrm{pH}$ value for decomposition of DMP via WOP at various pressures. $\bigcirc, \triangle,+$, and $\times: P_{T}=2.41,2.76,3.10$, and $3.45 \mathrm{MPa}$. $C_{0}=100 \mathrm{mg} \mathrm{L}^{-1}, V_{L}=400 \mathrm{~mL}, T=483 \mathrm{~K}$, and $\mathrm{Nr}=$ $500 \mathrm{rpm}$. Working gas after time $=0_{f}$ is $\mathrm{O}_{2}$. $\uparrow$ : Mean and Standard deviation (SD, $n-1$ method) at $t=0_{i}: 5.2 \pm 0.2$ and at $t=0_{f}: 4.1 \pm$ 0.2 .

It is noted that the $P_{T}$ was the sum of partial pressures of oxygen $\left(P_{\mathrm{O}_{2}}\right)$ and water vapor $\left(P_{\mathrm{WV}}\right)$. The saturation $P_{\mathrm{WV}}$ varies with temperature and is about $2.3 \mathrm{MPa}$ at $483 \mathrm{~K}$ [27]. Setting $P_{T}$ at 2.41 and $3.45 \mathrm{MPa}$ gave $P_{\mathrm{O}_{2}}$ of 0.11 and $1.15 \mathrm{MPa}$, respectively, for supplying the oxygen for mineralization reaction. Referring to the study of Lin and Ho [27] using
$2.5 \mathrm{MPa}$ as the lowest setting at $473 \mathrm{~K}$, this analysis thus did not employ $P_{T}$ lower than $2.41 \mathrm{MPa}$ at $483 \mathrm{~K}$.

3.4. Mechanism of Two-Stage Decomposition of DMP via WOP. In this test, the reactions are involved in components of DMP, oxygen, intermediate products, and ultimate end products of $\mathrm{CO}_{2}$ and $\mathrm{H}_{2} \mathrm{O}$. The intermediates are the decomposed short-chain hydrocarbon fragments which are acidic as reflected by the low $\mathrm{pH}$ value. Accordingly, the mechanism of two-stage decomposition of DMP via WOP may be depicted in Figure 10. In the heating stage without oxygen, DMP is essentially hydrothermally decomposed to acidic fragments lowering the $\mathrm{pH}$ value with significant $\eta_{\mathrm{DMP}}$, while forming little $\mathrm{CO}_{2}$ with low $\eta_{\text {TOC }}$. With the introduction of oxygen in the second stage, oxidation of DMP and its decomposed fragments takes place, destructing them into short-chain acids such as aliphatic acids or more completely to $\mathrm{CO}_{2}$ and $\mathrm{H}_{2} \mathrm{O}$. The produced $\mathrm{CO}_{2}$, however, was kept within the closed-batch reaction system in this study.

The stoichiometry equation for the forward oxidation reaction of DMP can expressed as follows:

$$
\mathrm{C}_{10} \mathrm{H}_{10} \mathrm{O}_{4}+10.5 \mathrm{O}_{2} \longrightarrow 10 \mathrm{CO}_{2}+5 \mathrm{H}_{2} \mathrm{O}
$$

For complete mineralization of DMP, each mole DMP consumes 10.5 moles of $\mathrm{O}_{2}$ while producing 10 moles of $\mathrm{CO}_{2}$. The $\mathrm{CO}_{2}$ partial pressure contributed from the complete mineralization of DMP is about $0.045 \mathrm{MPa}$ by consuming $0.047 \mathrm{MPa} \mathrm{O}$. This reaction reduces the total pressure slightly. In fact, the oxygen is not a limited factor because 


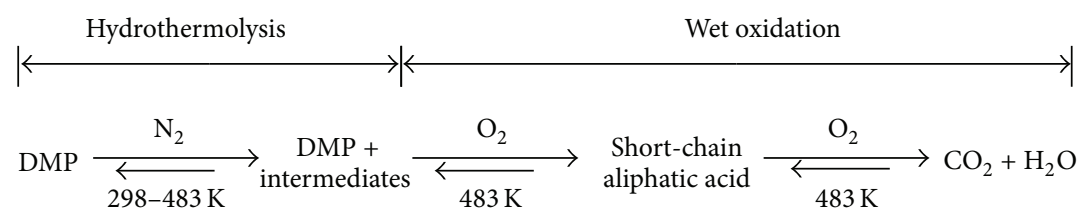

FIgURE 10: Two stages for the decomposition of DMP via WOP.

the minimum pressure applied is $2.41 \mathrm{MPa}$ exceeding the need. However, the mineralization of reaction (1) is hindered by the accumulation of product $\mathrm{CO}_{2}$ in the closed-batch reaction system. It forces the backward reaction of reaction (1) according to Le Chatelier's principle [31]. The equilibrium balance of the forward and backward reaction thus limits the complete mineralization of DMP. A release of $\mathrm{CO}_{2}$ gas out from the reaction system would certainly assist approaching the complete mineralization of DMP.

3.5. Comparison with Results of Others. Comparison of the results of this study with others is illustrated in Table 2. The present WOP can reach $\eta_{\text {DMP }}$ of $93 \%$ as high as the advanced methods (AMs) of electrochemical oxidation, photocatalytic degradation, and photocatalytic ozonation. The $\eta_{\text {TOC }}$ of WOP of $36 \%$ is lower than those of the aforementioned AMs at some conditions, however, comparable at other conditions. It is noted that the WOP simply uses oxygen with demand of the thermal energy, while other AMs need to employ chemical agents, catalysts, and ozone along with electric or UV energies. Thus, the WOP is comparatively simple to apply. The discrepancy of incomplete mineralization of WOP may be consummated with the postbiological treatment if necessary [20]. The predecomposition of DMP by WOP certainly greatly enhances the followed biological processing.

\section{Conclusions}

This study treated the toxic endocrine disrupter substance (EDC) of DMP via wet oxidation using oxygen (WOP) without other oxidant additives, being beneficial to the subsequent biological process if necessary, while avoiding the treatment of unwanted oxidant residues. The WOP effectively decomposed the DMP, indicating its feasible application for the treatment of other EDCs.

Among the three factors investigated, namely, rotation speed $\mathrm{Nr}$, reaction temperature $T$, and operation pressure $P_{T}$, the effects of $T$ are most significant. The proper conditions found are at $483 \mathrm{~K}, 2.41 \mathrm{MPa}$, and $500 \mathrm{rpm}$. The $\eta_{\mathrm{DMP}}$ and $\eta_{\text {TOC }}$ of $93 \%$ and $36 \%$, respectively, can be achieved at $180 \mathrm{~min}$. The produced $\mathrm{CO}_{2}$ kept in the closed-batch reaction system seems to resist the further mineralization reaction from intermediates. The application of sequential release of $\mathrm{CO}_{2}$ while addition of $\mathrm{O}_{2}$ to improve the $\eta_{\text {TOC }}$ is thus suggested.

\section{Conflict of Interests}

The authors declare that there is no conflict of interests regarding the publication of this paper.

\section{Acknowledgment}

The authors are grateful for the financial supports of this research provided by the Ministry of Science and Technology (formerly the National Science Council) of Taiwan.

\section{References}

[1] M. J. Bauer, R. Herrmann, A. Martin, and H. Zellmann, "Chemodynamics, transport behaviour and treatment of phthalic acid esters in municipal landfill leachates," Water Science and Technology, vol. 38, no. 2, pp. 185-192, 1998.

[2] M. Zhang, S. Liu, H. Zhuang, and Y. Hu, "Determination of dimethyl phthalate in environment water samples by a highly sensitive indirect competitive ELISA," Applied Biochemistry and Biotechnology, vol. 166, no. 2, pp. 436-445, 2012.

[3] J. P. Sumpter, "Endocrine disrupters in the aquatic environment: an overview," Acta Hydrochimica et Hydrobiologica, vol. 33, no. 1, pp. 9-16, 2005.

[4] C. A. Staples, D. R. Peterson, T. F. Parkerton, and W. J. Adams, "The environmental fate of phthalate esters: a literature review," Chemosphere, vol. 35, no. 4, pp. 667-749, 1997.

[5] W. Den, H. C. Liu, S. F. Chan, K. T. Kin, and C. Huang, "Adsorption of phthalate esters with multiwalled carbon nanotubes and its application," Journal of Environmental Engineering and Management, vol. 16, no. 4, pp. 275-282, 2006.

[6] A. J. Kumar and C. Namasivayam, "Uptake of endocrine disruptor bisphenol-A onto sulphuric acid activated carbon developed from biomass: equilibrium and kinetic studies," Sustainable Environment Research, vol. 24, no. 1, pp. 73-80, 2014.

[7] M. F. N. Secondes, V. Naddeo, F. J. Ballesteros, and V. Belgiorno, "Adsorption of emerging contaminants enhanced by ultrasound irradiation," Sustainable Environment Research, vol. 24, no. 5, pp. 349-355, 2014.

[8] D. W. Liang, T. Zhang, H. H. P. Fang, and J. He, "Phthalates biodegradation in the environment," Applied Microbiology and Biotechnology, vol. 80, no. 2, pp. 183-198, 2008.

[9] D. L. Wu, B. L. Hu, P. Zheng, and Q. Mahmood, "Anoxic biodegradation of dimethyl phthalate (DMP) by activated sludge cultures under nitrate-reducing conditions," Journal of Environmental Sciences, vol. 19, no. 10, pp. 1252-1256, 2007.

[10] D. L. Wu, Q. Mahmood, L. L. Wu, and P. Zheng, "Activated sludge-mediated biodegradation of dimethyl phthalate under fermentative conditions," Journal of Environmental Sciences, vol. 20, no. 8, pp. 922-926, 2008.

[11] C.-C. Chang, C.-Y. Chiu, C.-Y. Chang et al., "Combined photolysis and catalytic ozonation of dimethyl phthalate in a highgravity rotating packed bed," Journal of Hazardous Materials, vol. 161, no. 1, pp. 287-293, 2009. 
[12] Y.-H. Chen, L.-L. Chen, and N.-C. Shang, "Photocatalytic degradation of dimethyl phthalate in an aqueous solution with $\mathrm{Pt}$ doped $\mathrm{TiO}_{2}$-coated magnetic PMMA microspheres," Journal of Hazardous Materials, vol. 172, no. 1, pp. 20-29, 2009.

[13] Y.-H. Chen, N.-C. Shang, L.-L. Chen et al., "Photodecomposition of dimethyl phthalate in an aqueous solution with UV radiation using novel catalysts," Desalination and Water Treatment, vol. 52, no. 16-18, pp. 3377-3383, 2014.

[14] Y. Jing, L. Li, Q. Zhang, P. Lu, P. Liu, and X. Lü, "Photocatalytic ozonation of dimethyl phthalate with $\mathrm{TiO}_{2}$ prepared by a hydrothermal method," Journal of Hazardous Materials, vol. 189, no. 1-2, pp. 40-47, 2011.

[15] W. Jiang, J. A. Joens, D. D. Dionysiou, and K. E. O’Shea, “Optimization of photocatalytic performance of $\mathrm{TiO}_{2}$ coated glass microspheres using response surface methodology and the application for degradation of dimethyl phthalate," Journal of Photochemistry and Photobiology A: Chemistry, vol. 262, pp. 713, 2013.

[16] Y. Wang, Y. Liu, T. Liu et al., "Dimethyl phthalate degradation at novel and efficient electro-Fenton cathode," Applied Catalysis B: Environmental, vol. 156-157, pp. 1-7, 2014.

[17] F. L. Souza, J. M. Aquino, K. Irikura, D. W. Miwa, M. A. Rodrigo, and A. J. Motheo, "Electrochemical degradation of the dimethyl phthalate ester on a fluoride-doped $\mathrm{Ti} / \beta-\mathrm{PbO}_{2}$ anode," Chemosphere, vol. 109, pp. 187-194, 2014.

[18] F. Charest and E. Chornet, "Wet oxidation of active carbon," Canadian Journal of Chemical Engineering, vol. 54, no. 6, pp. 190-196, 1976.

[19] Y.-H. Chen, D.-C. Hsieh, and N.-C. Shang, "Efficient mineralization of dimethyl phthalate by catalytic ozonation using $\mathrm{TiO}_{2} / \mathrm{Al}_{2} \mathrm{O}_{3}$ catalyst," Journal of Hazardous Materials, vol. 192, no. 3, pp. 1017-1025, 2011.

[20] M. J. Dietrich, T. L. Randall, and P. J. Canney, "Wet air oxidation of hazardous organics in wastewater," Environmental Progress, vol. 4, no. 3, pp. 171-177, 1985.

[21] S. Imamura, H. Kinunaka, and N. Kawabata, "The wet oxidation of organic compounds catalyzed by Co-Bi complex oxide," Bulletin of the Chemical Society of Japan, vol. 55, no. 11, pp. 36793680, 1982.

[22] M. M. Ito, K. Akita, and H. Inoue, "Wet oxidation of oxygenand nitrogen-containing organic compounds catalyzed by cobalt(III) oxide," Industrials \& Engineering Chemistry Research, vol. 28, no. 7, pp. 894-899, 1989.

[23] J. Levec, M. Herskowitz, and J. M. Smith, "Active catalyst for oxidation of acetic-acid solutions," AIChE Journal, vol. 22, no. 5, pp. 919-920, 1976.

[24] L. X. Li, P. S. Chen, and E. F. Gloyna, "Generalized kinetic-model for wet oxidation of organic-compounds," AIChE Journal, vol. 37, no. 11, pp. 1687-1697, 1991.

[25] W. H. Li, J. L. Huang, H. Wang, A. J. Qi, and J. Xie, "Treatment of acrylic acid waste water by catalytic wet oxidation," Journal of Jilin Institute of Chemical Technology, vol. 24, no. 3, pp. 3-6, 2007.

[26] S. H. Lin and Y. F. Wu, "Catalytic wet air oxidation of phenolic wastewaters," Environmental Technology, vol. 17, no. 2, pp. 175181, 1996.

[27] S. H. Lin and S. J. Ho, "Treatment of high-strength industrial wastewater by wet air oxidation-a case study," Waste Management, vol. 17, no. 1, pp. 71-78, 1997.

[28] H. Lin Sheng and S. J. Ho, "Kinetics of wet air oxidation of high-strength industrial wastewater," Journal of Environmental Engineering, vol. 123, no. 9, pp. 852-858, 1997.
[29] V. S. Mishra, V. V. Mahajani, and J. B. Joshi, "Wet air oxidation," Industrial and Engineering Chemistry Research, vol. 34, no. 1, pp. 2-48, 1995.

[30] A. Sadana and J. R. Katzer, "Catalytic oxidation of phenol in aqueous solution over copper oxide," Industrial and Engineering Chemistry, vol. 13, no. 2, pp. 127-134, 1974.

[31] P. W. Atkins, "Principles of chemical equilibrium," in The Elements of Physical Chemistry, chapter 7, Oxford University Press, Oxford, UK, 3rd edition, 1993. 

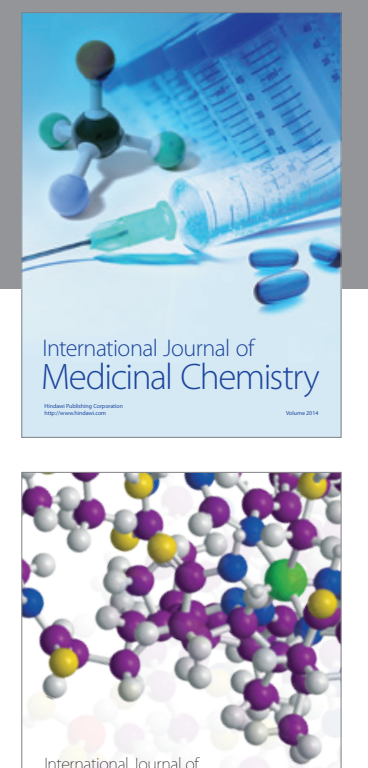

\section{Carbohydrate} Chemistry

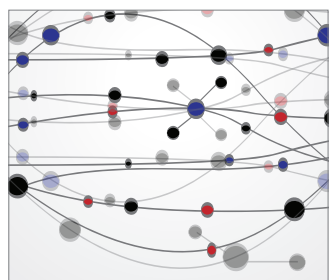

The Scientific World Journal
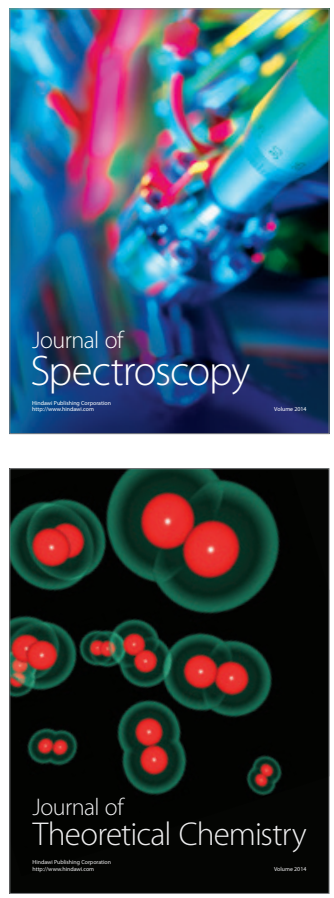
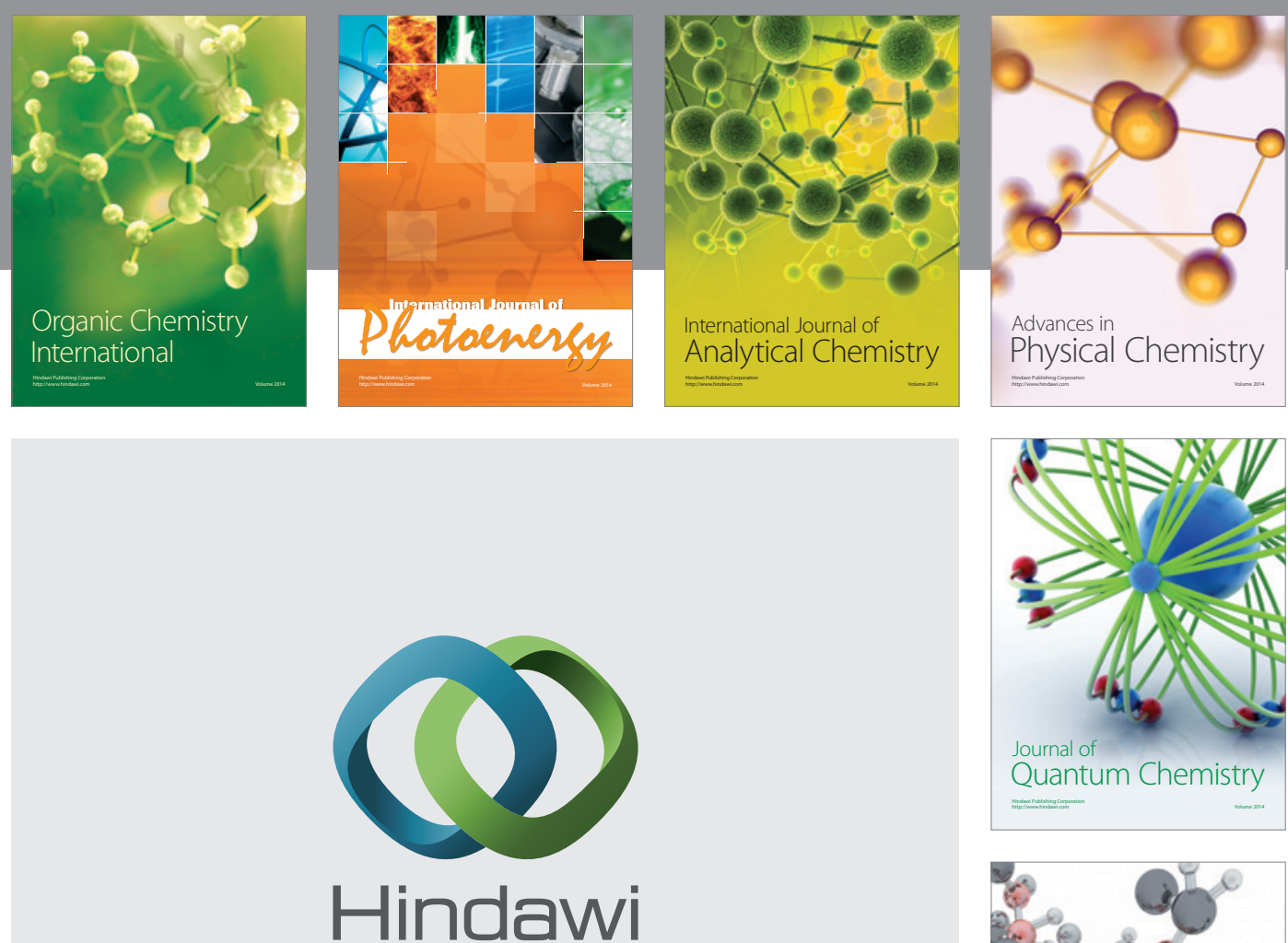

Submit your manuscripts at

http://www.hindawi.com

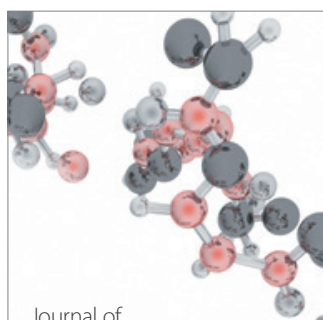

Analytical Methods

in Chemistry

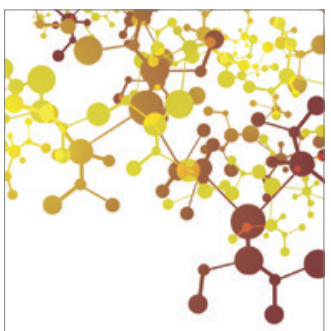

Journal of

Applied Chemistry

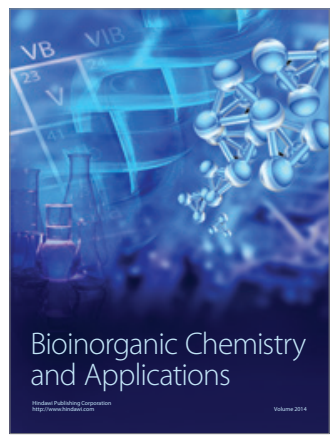

Inorganic Chemistry
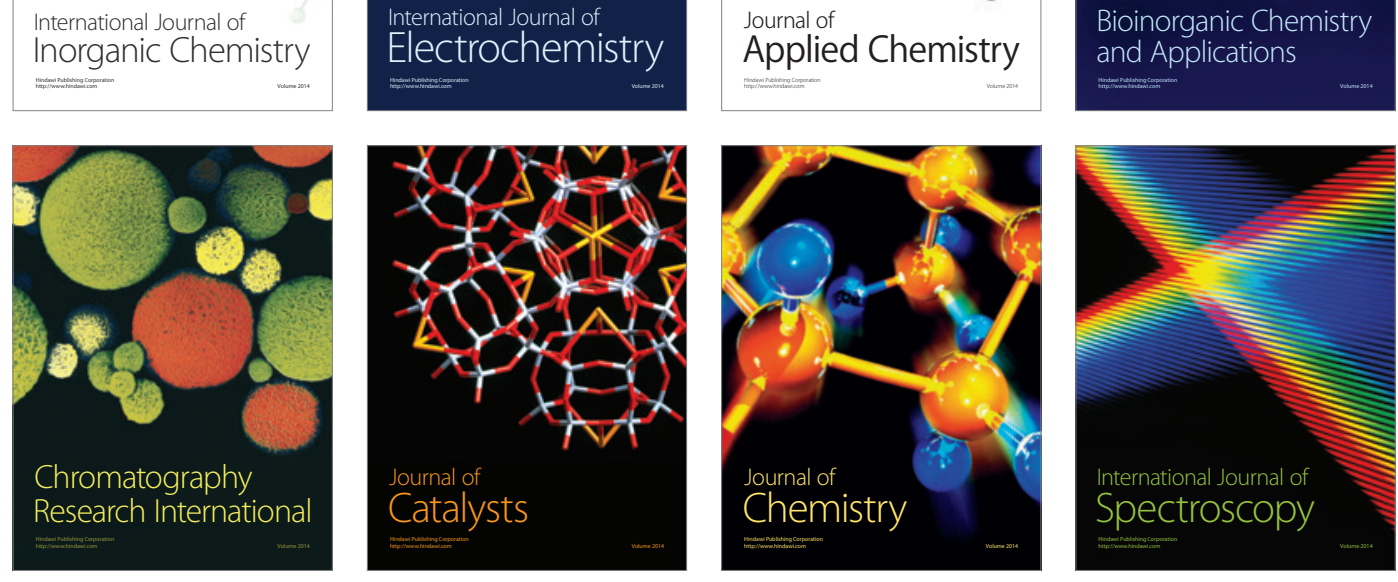